\title{
Development of Long-Term Forecast Energy Balances in the Power System of Siberia
}

\author{
Elena Malinovskaya ${ }^{1, *}$ \\ ${ }^{1}$ post-graduate student at Melentiev Energy Systems Institute, Siberian Branch of the Russian Academy of Sciences
}

\begin{abstract}
The article discusses the features of the development of long-term energy balances in the interconnected power system of Siberia (IPS). The main feature of the IPS of Siberia is a high proportion of hydro power plants and, as a result, a strong dependence of electricity generation on natural fluctuations in water inflow into reservoirs. In the power output of the HPPs of the Angara-Yenisei cascade, depending on the water availability conditions, the deviation from the long-term average values can be up to $30 \%$ or $31 \div$ 36 billion $\mathrm{kWh}$ per year. The development of long-term energy balances and an increase in the efficiency of the operation modes of the HPPs of the Angara-Yenisei cascade makes it possible to identify in advance possible risks in the operation of the water management system of the Angara-Yenisei basin and the unified energy system of Siberia, thereby ensuring a more balanced operation of the power system as a whole.
\end{abstract}

\section{Introduction}

In the structure of generating capacities of the interconnected power system of Siberia (IPS), about $50 \%$ are hydro power plants, including 30\% Angarsk HPP cascade and $20 \%$ - Yenisei. For comparison, the share of hydro power plants in the Unified Energy System of Russia accounts for about $18 \%$ of the installed capacity of all power plants. The share of hydro power plants in other energy systems is much lower: North-West - $12 \%$; Center $-10 \%$, Urals - $3 \%$ [1].

The main feature of the power system with a high share of hydro power plants is the large dependence of electricity generation on a natural factor - natural fluctuations in water inflows into reservoirs. In the power output of the HPPs of the Angara-Yenisei cascade, the deviation from the longterm average values can be up to $30 \%$ or $31 \div 36$ billion $\mathrm{kWh}$ per year.

Problems in the energy system of Siberia and the water management and socio-economic systems closely related to it arise when the water inflow into reservoirs deviates from normal and close to normal conditions. In dry periods, especially extreme ones, the production of electricity is significantly reduced, a deficit of the energy balance appears in certain sections of the IPS, and the reserves in reservoirs of long-term regulation decrease. In general, the overall reliability and stability of the functioning of both the power system and the water management system decreases. In high-water years, on the contrary, in the summer there is a problem of excess electricity generation at hydro power plants.

Consequently, the presence in the power system of a powerful cascade of hydro power plants is both an advantage (the use of cost-effective and environmentally friendly renewable energy resources) and a disadvantage of the power system. The main disadvantage is the uncertainty of the available water resources of the HPP reservoirs in the estimated time period. The reason is the natural, stochastic nature of the river flow.

Long-term planning of hydro power plants modes is associated with the extreme complexity of long-term forecasting of water inflows into reservoirs. Currently, Roshydromet gives a probable (interval) forecast of inflow for the coming month at the end of the previous month (until the 25th day) and once a quarter - for 3 months. There are no forecasts for a more distant period. At the same time, planning and forecasting in the electric power industry is carried out for the future up to 1 year or more [2-5]. This is due to the need to form a long-term planned balance of electricity and capacity in the power system. This balance allows, in turn, to plan in advance the supply of electricity and heat to TPPs, to form fuel reserves, to plan repairs of power equipment and electrical networks, and to solve other problems. In the absence of forecast indicators of water inflows into reservoirs for a period of more than 3 months, long-term forecasting and planning of energy balances, as a rule, use statistical data for the past period in the form of average long-term and monthly average indicators. In this case, indicators are usually used that correspond to normal ones. Such planning and forecasting gives acceptable results under normal conditions (close to the long-term average), but is not justified under other conditions, especially during periods of extreme water availability.

Thus, there is a need to improve the current system for planning the operating modes of hydro power plants as part of two interconnected systems - energy and water management. For this, it is necessary to form long-term forecast energy balances of the Siberian energy system, taking into account the use of forecast scenarios of water inflows into reservoirs for a period of up to 1 year with a

Corresponding author: lena.617244@ mail.ru 
monthly resolution and their monthly correction. It is required to model hydro power plants modes based on inflow scenarios for given energy and water management constraints for reservoir modes, taking into account the requirements of other water users, repair of equipment and electrical networks, dispatch schedules with the formation of aggregated estimates for individual hydro power plants and the cascade of hydro power plants as a whole, energy companies, regional power systems.

\section{Development of predictive energy plans in the energy system of Siberia}

In the current system of planning and management of the electric power industry, the electric power balances of the IPS of Siberia are developed in order to test the technical feasibility of providing the required annual electricity generation by power plants taken into account in the power balance, to determine the volume of power flows between power systems and the power plants' need for fuel [6].

The main tasks of forming the forecast balance of electrical energy and capacity in the interconnected power system are to cover the load of consumers and ensure the standard power reserve (for the IPS of Siberia - $22 \%$ of the maximum power consumption of the power system), assess the power system balance in terms of power [7].

To draw up forecast balances of electric energy and capacity, information is needed on the maximum power consumption, as well as the available (operating) capacity of power plants.

The expenditure part of the balance of electric energy and capacity of the IPS of Siberia takes into account the consumption of electric energy and the planned transmission of electric energy to other energy systems, including the export of electric energy to the energy systems of foreign countries (Kazakhstan, Mongolia).

The income part of the balance of electrical energy and power of the energy system takes into account the generation of electrical energy by the power plants of the IPS of Siberia and the planned receipt of electrical energy from other energy systems, including the import of electrical energy from the energy systems of foreign countries (Kazakhstan, Mongolia).

In accordance with the current Rules, two types of forecast balances of consumption and generation of electric energy and capacity are being developed: short-term and long-term [8].

The short-term balance is the basis for the operational management of the power system, the formation of dispatch schedules, the determination of the volume of electricity generation and the allocation of capacity reserves, the volume of purchase and sale of electricity and capacity on the market.

For a short-term balance (hour, day, week, month), it is necessary to use meteorological and hydrological information for the short term (Roshydromet data), the nature of the day (work, weekends), the need for electricity, heat energy, the state of the power system for the near future.

The long-term balance is used to form the annual summary balances of the production and consumption of electricity and capacity. This balance is the basis for longterm planning of operating modes of power plants, determination of the volume of necessary fuel reserves at TPPs, formation of repair schedules for generating equipment and power grid facilities.

For a long-term balance (month, quarter, season, year and more), scenario approaches are required to assess the general economic, energy, balance situation using scenarios of hydrological, climatic conditions, electricity / power consumption. In this case, natural factors play a key role: air temperature, water inflow into reservoirs, and others.

This article discusses the development of long-term energy balances.

\section{Development of long-term forecast energy balances in the energy system of Siberia}

In the practice of power system management, it is customary to develop long-term balances of electrical energy for the conditions of low-water and high-water periods, since the volume of consumption of electrical energy and power, which does not cover HPPs, is distributed to TPPs [6].

In addition, an important feature of the IPS of Siberia is work with a forced condensation load due to the presence of predominantly thermal power units (TGK, CHPP) in the power system, as well as the operation of thermal power units in the summer period at a technical minimum due to the lack of the possibility of work on PCU (reductioncooling unit) or shutdown of power units. Condensing units (GRES) close the balance of generation and consumption of electric energy and in the absence of demand in the summer they stop.

The distribution of the projected volume of electricity production at TPPs within the IPS of Siberia should be determined based on the results of an assessment of the regime and balance situation, taking into account the generation of HPPs, the throughput of electrical networks and forecasts of its change in accordance with plans for the construction, repair of power equipment, power grid facilities the priority of the maximum use of highly economical generating equipment and taking into account the permissible modes of its operation [8].

When forming long-term balances of electric energy and power, the following should be provided:

1. balance of consumption and production of electrical energy and power;

2. reliability and efficiency of production and transmission of electric and heat energy;

3. fulfillment of annual repair schedules for main power equipment and electrical networks.

When developing and forming forecast long-term balances of production and consumption of electricity and capacity, scenario approaches are needed to assess the general economic, general energy, balance situation using scenarios of hydrological and climatic conditions. Longterm planning should include: 


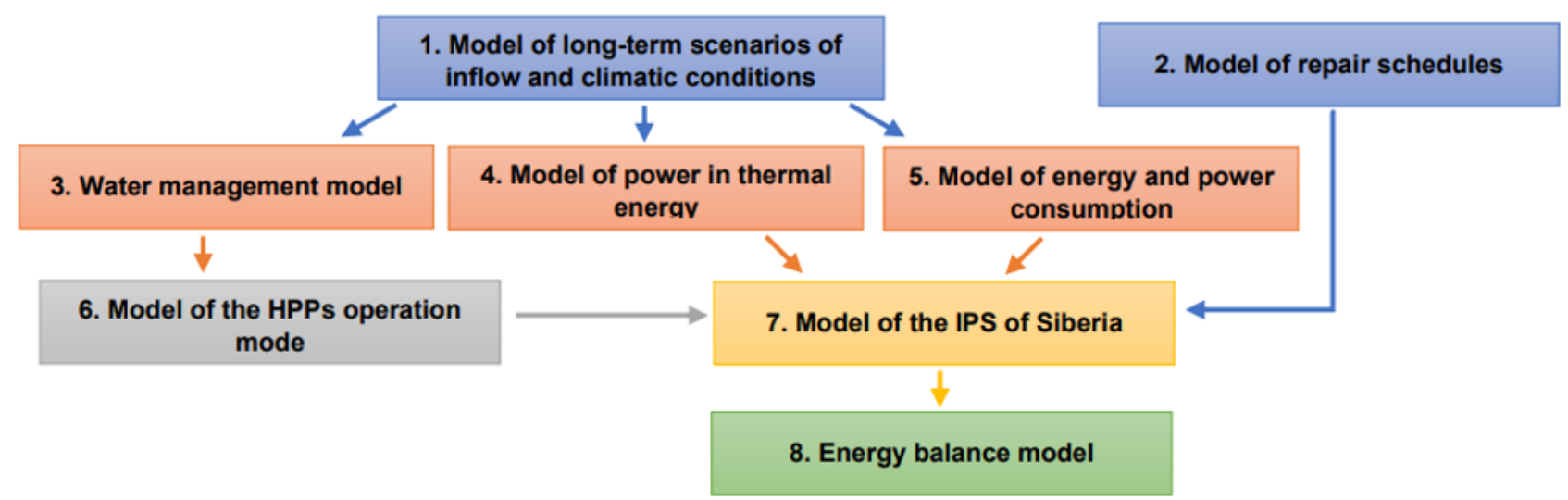

Fig. 1. A system of models for comprehensive studies of long-term modes and the formation of long-term energy balances of the IPS of Siberia

1. compilation of annual, quarterly, monthly balances of consumption and production of electricity and capacity;

2. long-term scenarios of water inflows into reservoirs and climatic conditions (changes in summer and winter temperatures);

3. drawing up annual and monthly schedules for the repair of main power equipment (including equipment leading to a decrease in power), electrical networks;

4. reduction of specific fuel consumption for the generation of electric and heat energy, as a result, minimization of total fuel costs.

When developing long-term forecast energy balances in the Siberian energy system, it is necessary to take into account the following factors and dependencies:

1. The generation of HPPs of the Siberian power system, depending on:

$>$ the level of available reserves of hydro resources at the beginning of the water year (special attention is paid to the main reservoir of long-term regulation - Bratsk);

$>$ scenarios of water inflow into HPPs reservoirs (for Irkutsk - Lake Baikal, Bratsk and Krasnoyarsk reservoirs - for the entire period; for Boguchansk, UstIlimsk and Sayano-Shushenskiy - for the spring flood period);

$>\quad$ repair schedule for power equipment and power grid facilities;

$>$ maximum throughput capacity of hydroelectric facilities, taking into account the repair campaign;

$>$ water requirements (water transport during the navigation period, ice restrictions, etc.).

2. The generation of TPPs of the Siberian power system, depending on:

$>$ supply of thermal energy to consumers (heating, ventilation, hot water supply, technologies with a heat carrier in the form of hot water or steam);

$>\quad$ the volume of generation of hydro power plants of the IPS of Siberia.

$>$ schedule of repair of power lines and electrical equipment.

3. Operating modes of the power system, taking into account demand (consumption) and supply (generation), as well as the possibility of "Issuing" or "Receiving" electricity and power to / from adjacent power systems.
For the formation of long-term forecast energy balances, it is necessary to take into account the above factors and dependencies.

\section{A system of models for the study of long-term modes and the formation of long-term energy balances of the Siberian power system}

For a comprehensive study and compilation of predicted long-term energy balances in the energy system of Siberia, a system of models has been developed, which includes eight main blocks - models (Fig. 1):

1. Model of long-term scenarios of inflow and climatic conditions.

2. Model of repair schedules.

3. Water management model.

4. Model of power in thermal energy.

5. Model of energy and power consumption.

6. Model of the HPPs operation mode.7. Model of the IPS of Siberia.

8. Energy balance model.

Each block includes several models (simulation, optimization and multicriteria) that solve various problems, taking into account the uncertainty of water inflows into reservoirs, the amplitude and frequency of temperature anomalies in the regions under study, the requirements of water users, the volume of electricity consumption, forced and planned repairs of electrical equipment and electrical networks, restrictions on the limiting throughput of individual sections of the power grid in controlled sections, other factors and restrictions.

The proposed system of models provides, on the basis of probabilistic long-term scenarios of water inflows into reservoirs and expected temperature regimes, to obtain optimal balanced regimes of water management and energy systems while ensuring the reliability and continuity of energy and water supply to consumers in any considered time interval.

\subsection{Model of long-term scenarios of inflow and climatic conditions}


Dispatch schedules currently used in the current management of hydro power plants are based on the statistical characteristics of inflows and allow to control the levels of reservoirs in accordance with the current total inflows and the achieved water levels in each reservoir. However, they do not allow for long-term planning of the work of water users and water consumers. In this regard, the development of scenarios of water inflows for the future seems to be an important condition.

In the practice of regulating the regimes of hydro power plants, at present, along with the dispatch schedules, a series of statistical hydrological indicators and forecasts of water content provided by Roshydromet for a period of up to 1-3 months are used.

This approach does not meet the modern needs of water management and energy organizations that carry out longterm management and planning of regimes for a period of up to 1 year or more. In addition, due to global and regional climate changes, the use of only hydrometeorological statistics for predictive estimates of water content becomes ineffective. Given the significant advances in the creation and use of global climate models over the past decades, it seems appropriate to use them for long-term assessments of water content. One such model is the global climate model CFS-2 (Climate Forecast System), developed at the EMC (Environmental Modeling Center), which is part of the international organization NCEP (National Centers for Environmental Prediction). On its basis, the prognostic ensembles of the state of the atmosphere and ocean are updated daily with a time interval from several hours to 9 months for the entire globe. The ensemble approach used in the model makes it possible to form probabilistic estimates of the state of the atmosphere for the long term (up to 1 year).

To monitor, accumulate and process the results of modeling water content and climatic changes, ESI SB RAS has developed special methods, software and components that allow to quickly form long-term estimates of precipitation, temperatures, pressure, geopotential on the territory of the river basins of the energy system under study $[9,10]$.

Based on the processing of forecast ensembles of meteorological indicators in the region under consideration, analogous years are determined that are closest in terms of the characteristics of the state of the atmosphere. Based on the found analogs, estimates of inflows into the reservoirs of the cascade are formed in the form of ranges of probability distributions. The most important period for planning the operating modes of the water management system in Siberia is the period from April to October. The final forecast scenarios are determined by an automated procedure with the rejection of unlikely events, the processing of regression dependencies and connections of meteorological indicators with river flows and the refinement of their boundaries based on expert estimates generated by other models. Temperature regimes are formed in the form of anomalies in their spatial distributions. In Siberia, the temperature regime is essential for planning the power system regimes during the winter heating season (from November to March), when the possible production and consumption of thermal electricity varies within wide limits [9].

\subsection{Model of repair schedules}

Annual and monthly schedules for the repair of dispatching facilities should ensure the possibility of fulfilling all the planned outlets for the repair of dispatching facilities provided that the level of electricity consumption predicted for the corresponding period in the Unified Energy System of Russia, IPS of Siberia and in technologically isolated territorial power systems is ensured [11].

The annual schedule for the repair of dispatch facilities includes dispatch facilities, the decommissioning and shutdown of which is necessary for scheduled maintenance, reconstruction and modernization of power facilities.

Monthly repair schedules for dispatch facilities are developed by the System Operator taking into account annual repair schedules.

When drawing up monthly repair schedules, the timing of the withdrawal for repair and the composition of dispatch facilities taken out for repair of equipment and networks are determined taking into account the proposals of the owners and other owners of dispatch facilities sent to the authorized dispatch center. Proposals containing adjustments to the timing of the withdrawal for repair and the composition of dispatch facilities to be repaired should contain information about the current state of dispatch facilities, repair measures performed in the previous period, as well as the applicant's ability to carry out previously planned repairs.

The main tasks of the repair campaigns are overhaul, reconstruction and modernization, as well as current repairs, leading to the limitation of consumers of electrical energy and capacity.

\subsection{Water management model}

The system includes hydrological models based on water balance equations, hydraulic models for estimating the travel time of a water flow to various points of the river network, water management models to take into account the constraints of all water users and water consumers, as well as environmental and social constraints. With the help of dispatch schedules for level regime control and given scenarios of water inflows into reservoirs, prognostic scenarios of discharges through hydro power plants are formed. The models used are developed at the ESI SB RAS [10].

\subsection{Model of power in thermal energy}

The demand for thermal energy (heating, ventilation, hot water supply, technologies with a heat carrier in the form of hot water or steam) is characterized by daily, seasonal, interannual variability associated with the intensity of the utilization of enterprises and the temperature regime in the served territories.

The model for the formation of long-term scenarios of demand for thermal energy is based on statistical data for various temperature regimes, which make it possible to form regression dependences, with the allocation of periods of maximum and minimum consumption in 
seasonal resolution. The existing heat demand targets are also used.

\subsection{Model of energy and power consumption}

The consumption of electric energy and power in the power system is of a probabilistic nature, characterized by daily, seasonal, interannual variability associated with the intensity of the intra-annual load of enterprises, the temperature regime in the served areas, which significantly affects the volume of electricity generation, as well as with the possible introduction of additional planned and unscheduled consumers.

Models for the formation of long-term scenarios of electricity and power consumption are based on the accumulated statistics for various temperature regimes, which make it possible to form regression dependences, with the identification of periods of maximum and minimum consumption in daily and seasonal resolutions. The existing planned indicators of the need for electricity and capacity, commissioning of new large consumers of electricity are also used.

\subsection{Model of the HPPs operation mode}

The power and electricity generation at individual hydro power plants varies widely, which is associated with seasonal and interannual irregularities in water inflows into reservoirs and operating modes of the power system at different time intervals in accordance with load schedules. For a cascade of hydro power plants, as a rule, the interannual unevenness of inflows decreases, with the exception of cases of global low-water and high-water periods, covering large river basins.

When modeling hydro power plants modes according to the formed scenarios of water inflows into reservoirs, the following tasks are solved:

1. Clarification of water consumption according to dispatch schedules.

To determine the effective modes of hydro power plants in the given restrictions on costs formed in the model of the water management system, for each moment of time (day, decade, month, quarter, water management year), the ranges of costs are specified according to the dispatch schedules of each hydro power plants, taking into account the planned repairs that are formed in repair schedule models.

2. Determination of costs when solving the problem of cascade regulation according to the criterion of maximizing electricity generation for the entire cascade.

The results of this model are the permissible (possible) ranges of electricity generation by each HPPs, the HPPs cascade as a whole, and indicators of the used capacity for different periods of time.

For power systems with a high share of hydro power plants, the main risks of regime control are idle discharges through the drainage structures of hydro facilities, as well as increased electricity generation in the summer in the absence of appropriate demand and (or) the impossibility of its use (transmission) in full the impossibility of ensuring the guaranteed capacity of the hydro power station.

To simulate the modes of individual hydro power plants and a cascade of hydro power plants, the model and software developed at the ESI SB RAS are used [10].

\subsection{Model of the IPS of Siberia}

Depending on the tasks to be solved, among which may be increasing the reliability and stability of the power system, increasing the economic efficiency of its operation, assessing and minimizing various risks, preventing or reducing possible damage, rational planning of repairs, the formation of fuel reserves at thermal power plants and others, various formulations are possible models of power systems. In this case, modeling power systems is reduced to solving an optimization problem, where the objective function reflects the criterion of the efficiency of the power system, and the constraints consist of balance constraints and constraints on variables. The main parameters for the operation of the block of power system models are longterm scenarios of consumption of electric and thermal energy in the annual, seasonal, monthly, weekly, daily and hourly sections; permissible operating modes of hydro power plants, taking into account all water management and energy restrictions, repair schedules for power equipment, transmission lines and power grid facilities.

The model developed at ESI SB RAS is also used as the basic model of the IPS of Siberia [10].

\subsection{Energy balance model}

One of the criteria for modeling the operation of the power system can be to minimize the cost of generating electricity, given the known consumption characteristics of generating stations, the required levels of consumer loads in territorial energy zones, the throughput of inter-zone communications, expenses for auxiliary needs and the coefficients of power losses in the transmission lines of inter-zone communications.

When solving this block of the model, it is necessary to determine the optimal load of power plants (hydro power plants, thermal power plants), taking into account a number of technical restrictions on the operation of the power system and its facilities, as well as the presence of a potential surplus or deficit of generating capacity.

The main task of the energy balance model is to draw up a balance of electricity and capacity for a period from one month to one year, taking into account the optimization for each hour of the billing period in order to maximize energy efficiency with favorable price offers on the WEM (wholesale electricity market) for generating companies.

\section{Conclusion}

The proposed system of models provides, on the basis of probabilistic long-term scenarios of water inflows into the reservoirs of HPPs of the Angara-Yenisei cascade and the expected temperature regimes, to obtain optimal balanced regimes of water management and energy systems while ensuring the reliability and continuity of 
energy and water supply to consumers in any considered time interval.

When forming long-term forecast energy balances of the IPS of Siberia, the system of models for a comprehensive study of long-term modes of water management and energy systems in Siberia, developed at the ESI SB RAS, can be used.

The development and assessment of long-term operating modes of the Angara-Yenisei cascade hydro power plants make it possible to identify in advance possible risks in the operation of the Angara-Yenisei basin water management system and the Siberian energy system for different hydrological and climatic scenarios. This creates potential opportunities for improving the efficiency of the energy system as a whole.

\section{References}

1. Gvozdev D.B., Kurbatov A.P. Problems of managing hydropower plants of Siberia in a new economic environment// Electrical stations. 2004, No. 3. pp. 62 - 67. In Russian.

2. Resolution of the Government of the Russian Federation of December 27, 2004 No. 854 "On Approval of the Rules for Operational Dispatch Management in the Electric Power Industry". Available at: http://base.garant.ru/187737/.

3. Decree of the Government of the Russian Federation of October 17, 2009 No. 823 "On schemes and programs for the long-term development of the electric power industry". Available at: http://www.consultant.ru/document/cons_doc_LAW 93016/.

4. Order of the Ministry of Energy of the RF of December 14, 2011 No. 600 "On approval of the Procedure for drawing up fuel and energy balances of the constituent entities of the RF and municipalities". Available at: http://base.garant.ru/70135702/.

5. Decree of the Government of the Russian Federation of 13.08.2018 No. 937 "Rules for the development and approval of schemes and programs for the prospects for the development of the electric power industry". Available http://base.garant.ru/72015900/.

6. Official site of JSC SO UES branch of ODU Siberia/ Available at: https://so-ups.ru/?id=odu_siberia.

7. GOST R 58057-2018 "Planning the development of power systems". Available at: https: https://base.garant.ru/191582/.

8. Rules for the technical operation of power plants and networks of the Russian Federation. Approved. by order of the Ministry of Energy of the Russian Federation of June 19, 2003 No. 229. Available at: https://base.garant.ru/186039/.

9. V.M. Nikitin, N.V. Abasov, and E.N. Osipchuk. Modeling of Long-term Operating Regimes of Hydro Power Plants as Part of Energy and Water Systems in the Context of Uncertainty // E3S Web of Conferences: ENERGY-21 - Sustainable Development \& Smart Management, Vol. 209, 2020. p.7. DOI:10.1051/e3sconf/202020905014.
10. Abasov N.V., Nikitin V.M., Osipchuk E.N. A System of Models to Study Long-Term Operation of Hydro Power Plants in the Angara Cascade // Energy Systems Research, Vol. 2, Number 2(6), 2019. P. 5 18.

11. Resolution of the Government of the RF of July 26, 2007 No. 484 "On the decommissioning of electric power facilities for repair and from operation". Available at: https://base.garant.ru/191582/. 